\title{
- AMOR DOS HOMENS AVULSOS, DE VICTOR HERINGER: UMA ANÁLISE NARRATOLÓGICA
}

O AMOR DOS HOMENS AVULSOS, BY VICTOR HERINGER: A NARRATOLOGICAL ANALYSIS

O AMOR DOS HOMENS AVULSOS, DE VICTOR HERINGER: UN ANÁLISIS NARRATOLÓGICO

Gabriel Arcanjo Santos de ALBUQUERQUE

Jamescley Almeida de SOUZA

\section{RESUMO}

Neste trabalho temos como objetivo realizar uma "análise narratológica" (REUTER, 2002) do mais famoso romance do escritor carioca, de ascendência germânica, Victor Heringer, falecido em 2018. Na tarefa a que nos propomos, em $O$ amor dos homens avulsos, passamos pelos três niveis de análise - ficção, narração e textualização, apresentando uma descrição do romance. Entretanto, como nenhum texto pode fazer sentido sem as suas remissões a outros textos ou referências às realidades do mundo, destacamos, resumidamente, a principal temática trabalhada em O amor dos homens avulsos, que é a descoberta da homoeroticidade entre dois adolescentes.

PALAVRAS-CHAVE:

Análise narratológica,

Homoeroticidade; Victor Heringer.

\section{ABSTRACT}

In this paper we aim to perform a "narratological analysis" (REUTER, 2002) of the most famous novel written by the Carioca writer of Germanic descent, Victor Heringer, who died in 2018. In the task we propose, in 0 amor dos homens avulsos, we go through the three levels of analysis - fiction, narration and text production, presenting a description of the novel. However, since no text can make sense without its references to other texts or references to the realities of the world, we briefly highlight the main theme of o amor dos homens avulsos, which is the discovery of homoeroticity between two adolescents.

\section{KEYWORDS:}

Narratological analysis; Homoeroticity; Victor Heringer.

\section{RESUMEN}

En este trabajo tenemos como objetivo realizar un "análisis narratológico" (REUTER, 2002) de la más famosa novela del escritor carioca, de ascendencia germánica, Victor Heringer, fallecido en 2018. En la tarea a la que nos proponemos, en 0 amor dos homens avulsos, pasamos por los tres niveles de análisis - ficción, narración y textualización, presentando una descripción de la novela. Sin embargo, como ningún texto puede tener sentido sin sus remisiones a otros textos o referencias a las realidades del mundo, destacamos, brevemente, la principal temática trabajada en 0 amor dos homens avulsos, que es el descubrimiento de la homoeroticidad entre dos adolescentes.

PALABRAS-LLAVE:

Análisis narratológico;

Homoeroticidade; Victor Heringer. 


\section{INTRODUÇÃO}

Podemos distinguir, grosseiramente, que existem diversas maneiras de abordar, interpretar e compreender uma narrativa. Algumas delas podem partir especificamente do plano do conteúdo, trazendo em destaque o ponto de vista sociológico, psicanalítico, político, religioso etc., e, ainda outras podem recair sobre o plano da expressão, colocando em evidência a natureza das propriedades estéticas do texto literário. O primeiro desses tipos de análise, é importante ressaltar, põe em movimento valores extraestéticos; já o segundo, valores intraestéticos.

Após realizarmos a leitura do premiado romance de Victor Heringer (1988-2018), O amor dos homens avulsos (2016), optamos por levar adiante o segundo tipo de abordagem, elaborando uma "análise narratológica" do livro, descrita por Reuter (2002, p. 9) como aquela que "consiste em interessar-se pelas narrativas como objetos linguísticos, fechados em si". Essa afirmação pode trazer embutida em si a ideia de que iremos descuidar de um dos princípios fundamentais que presidem a análise narratológica, a saber, a relação do texto com o seu mundo exterior.

Dizemos isso porque a nossa abordagem - ou quem quer que se determine a analisar esse romance - poderia enveredar por um dos instigantes pontos de vista que ele sinaliza ou permite. Mas, o nosso objetivo aqui é levar a cabo uma "análise narratológica" (REUTER, 2002) de O amor dos homens avulsos, fundamentalmente por ser tratar de um romance recente, com pouco mais de dois anos de publicação, finalista de alguns prêmios de literatura no Rio de Janeiro e em São Paulo e alvo de julgamentos positivos de alguns críticos literários. Ao final, trazemos um olhar sobre a principal temática trabalhada na narrativa, que é a descoberta da homoeroticidade entre dois adolescentes durante o período da Ditadura Militar no Brasil.

\section{VICTOR HERING: O ESCRITOR E A SUA OBRA}

Consideramos oportuno deixar aqui algo relativo ao escritor, principalmente em razão de sua precoce e trágica morte no ano de 2018. O breve relato que realizaremos sobre Victor Heringer e a sua obra é menos uma tentativa de fazêlos conhecidos, haja vista que existe um cabedal de informações disponíveis sobre o assunto, do que uma forma de homenagear esse extraordinário talento carioca - de origem teutônica - que tão cedo nos deixou.

Victor Doblas Heringer nasceu em São Cristóvão, no Rio de Janeiro, mas foi criado em Nova Friburgo, região serrana do Estado. Graduou-se em Letras no ano de 2011, pela Universidade Federal do Rio de Janeiro, obtendo, pela mesma instituição, o grau de Mestre em Letras (Estudos Literários) em 2014. A sua produção literária inicia-se com obras de poesia, como Automatógrafo (2011), um livro de contos, Lígia (2014), incluindo ainda a tradução de First they killed my father, um livro de não-ficção escrito por Loung Ung, e termina com os romances Gloria (2012) e O amor dos homens avulsos, pelos quais, ele se destaca.

Em 2013, aos 25 anos de idade, Victor Heringer foi laureado com o Prêmio Jabuti pelo seu romance Gloria, que narra a saga da família Costa e Oliveira, e em 2016 chegou a ser finalista de três prêmios importantes com o romance O amor dos homens avulsos: Prêmio Rio de Literatura, Prêmio São Paulo de Literatura e o Oceanos (antigo Prêmio Portugal Telecom de Literatura). Atinente ao sucesso de seu labor literário, constitui um maciço fato que o falecimento precoce do jovem escritor, em razão de suicídio, fez com que houvesse no ano de 2018 um incremento na procura por elas e, consequentemente, crescimento nas vendas.

Mas, dito isso, importa-nos fechar esse breve relato. E, ao fazermos isso, declaramos enfaticamente que, caso o leitor queira se inteirar um pouco mais sobre o escritor Victor Heringer, de grande interesse seria a consulta do documento intitulado Notas avulsas sobre $\mathrm{O}$ amor dos homens avulsos, postado por ele mesmo no dia 6 de setembro de 2016. Encaremolo:

Olá, meu nome é Victor Heringer, nasci no Rio de Janeiro em 1988, cidade para a qual retorno, madaleno arrependido, mais ou menos de dois em dois anos. Tenho 1,86 de altura, peso uns $85 \mathrm{~kg}$, não fico bronzeado, só muito vermelho, mas gosto do mar e da praia. Entre a esquerda e a direita, costumo acreditar mais no abismo, embora seja escravo da utopia. Sou macumbeiro, vascaíno $e$, quando tenho que dizer uma profissão para anotarem nos formulários, digo que sou professor de português (HERINGER, 2016, on-line).

Devemos observar que antes de evidenciar que a saída desse livro é a ternura, o próprio escritor se apresenta ao seu público.

\section{O AMOR DOS HOMENS AVULSOS: UMA ANÁLISE NARRATOLÓGICA}

É razoável apontar que uma analise narratológica que põe em seu centro valores intraestéticos pode se dá em três níveis: o nível da ficção, o da narração e o da produção do texto. No primeiro nível são analisados, como ressalta Reuter (2002, p. 27), "o universo encenado pelo texto: a história, as personagens, o espaçotempo". Em seguida, relativamente à narração, são colocados em evidência o seu modo de apresentação, a saber, o tipo de narrador, a perspectiva escolhida, a ordem adotada etc. E o terceiro nível, por fim, remete às escolhas lexicais, sintáticas, retóricas e estilísticas: tipo de discurso, termos-chave, designação das personagens, o registro dominante (se próximo ou elevado do calão), figuras de estilo etc.

\section{FICÇÃO}

Para bem nos orientarmos, começamos pela história, afirmando que esta é composta pelas ações. Respeitante a um texto narrativo, devemos nos perguntar se elas são numerosas ou não, bem como se elas são de natureza interna ou externa à psicologia da personagem. No caso de $\mathrm{O}$ amor dos homens avulsos, nós temos um homem da altura de seus 53 anos como personagem principal (Camilo), trazendo à memória a sua infância vivida na época da Ditadura Militar no Brasil, relembrando - em especial - o seu primeiro amor por um menino (Cosme) adotado por seu pai.

Bem, por isso podemos afirmar que não estamos diante de um romance de aventura, mas de uma narrativa psicológica, uma vez que as ações não são numerosas e são, em sua essência, interior à psicologia de Camilo, ligadas a lembranças e a sentimentos interiores 
vividos por ele. Ei-lo rememorando: "nas férias de 1976, eu tinha uns treze anos de idade. O verão nem tinha começado de verdade e minha pele descascava pela terceira vez" (HERINGER, 2016, p. 12). Ou ainda: "naquele ano, Paulina minha babá teve uma filha chamada Adriana" (HERINGER, 2016, p. 32).

O caráter de ficcionalidade de um texto literário também pode ser examinado do ponto de vista de sua explicitação. Dito de outro modo, importa, acima de tudo, em averiguar se nele está claramente identificável o caráter ficcional ou não. Caso ele esteja, estamos diante de um "romance clássico" (REUTER, 2002, p. 29); do contrário, podemos estar "diante de um romance de vanguarda que anuvia a clareza narrativa" (REUTER, 2002, p. 29). Com referência ao $\mathrm{O}$ amor dos homens avulsos é pertinente admitir que esse caráter se encontra-se assinalável desde o seu paratexto, ou seja, aquilo que está ao redor do texto: capas, imagens, prefácio etc. Mesmo antes de abrir o texto, o livro traz um "informe meteorológico", o qual deixa claro que aquilo que temos diante de nós se trata de um romance: "a temperatura deste romance está sempre acima dos $310 \mathrm{C}$. Umidade relativa do ar: jamais abaixo dos 59\%" (HERINGER, 2016, p. 7).

Não obstante, a própria obra, não poucas vezes, procura lançar sombras sobre essa clareza ficcional, seja em seu paratexto ou dentro de sua narrativa, quando aplica técnicas que servem para configurar ares de realidade. Isso acontece, por exemplo, quando nove fotos do autor Victor Heringer ainda criança são inseridas na página 5 , ou quando traz carimbos e registros de protocolo oficiais do DOPS (Departamento de Ordem Política e Social), pois seu pai, o "doutor Pablo", colaborou com a Ditadura e "ajudava nos porões, mantendo os prisioneiros sobrevivos" (HERINGER, 2016, p. 37). Outros documentos implantados na narrativa e que ajudam nesse tom de realidade são o registro de frequência escolar do protagonista Camilo, com anotações, tais como: "faltou", "presente", "recesso", "advertido" e "domingo" (HERINGER, 2016, p.39), bem como o boletim escolar de Cosme Henrique de Souza, do primeiro bimestre do ano letivo de 1978 , reproduzido na página 47 , e diversas fotografias em preto e branco que auxiliam na ilustração do que está sendo narrado (HERINGER, 2016, p. 50, 76, 78, 91, 98, 106).

Talvez devamos esclarecer que esse tipo de técnica, a qual consiste em agregar aparências de realidade reproduzindo documentos, prospectos, fotografias, bibliografias, entre outros, foi descrita por Samoyault como um método que "implica ao mesmo tempo a existência de um documentarista ou de um colecionador, mas também de um 'colador', que faz o texto entrar numa espécie de mimésis generalizada, onde tudo teria o mesmo grau de realidade ou de irrealidade" (SAMOYAULT, 2008, p. 105).

Nesse mesmo passo, podemos argumentar que Victor Heringer, na representação feita em $\mathrm{O}$ amor dos homens avulsos, equipa-se com propriedade do húmus sociocultural de um tempo e de um lugar de onde o texto é proveniente, o qual também ajuda a conferir-lhe realidade. De modo breve, por tempo e por lugar, aqui, entendemos os dois anos anteriores à publicação desse romance, a saber, 2014 e 2015, assim como traços e valores socioculturais cariocas.

Não sem razão que vão aparecer no livro, não somente imagens do subúrbio da cidade do Rio de Janeiro, que é o bairro do Queím, construído ficcionalmente de forma mais explícita e detalhada em seu incipit, como referências diretas a um real que é tomado ou emprestado como fragmento dessa cultura e introduzido nessa arte, embaraçando as fronteiras entre ficção e realidade. Em linguagem mais técnica, ocorre o que Reuter descreve na seguinte passagem: "o texto, em incessante vaivém, vai misturar as remissões ao nosso universo, acabando por deixar imprecisas ou confusas as referências, ou ainda modificando, em cada ida ou vinda, alguns elementos" (REUTER, 2002, p. 53).

Nesse sentido, podemos citar a alusão à Companhia de Energia Light: "as ruas foram asfaltadas e as esquinas, arejadas pela Light" (HERINGER, 2016, p. 18); a menção ao ex-presidente Luiz Inácio Lula da Silva: "o Lula não é mais o presidente há anos, mas o Grumá é meu único amigo" (HERINGER, 2016, p. 50); o referimento a uma pesquisa publicada, no Brasil, por vários veículos de imprensa, dentre eles O Globo, no dia 9 de junho de 2014, intitulada "Rosto dos homens foi moldado por milhões de anos de soco, segundo estudo": "deu no jornal um dia desses: os cientistas descobriram que o rosto humano foi moldado para resistir aos socos. Temos esta cara porque a espécie passou milhões de anos levando porrada" (HERINGER, 2016, p. 61); a citação do acidente aéreo envolvendo o presidenciável Eduardo Campos, em 2014: "hoje é dia 13 de agosto, 2014. São $21 \mathrm{~h} 24$ e o jatinho do Eduardo Campos, candidato a presidente da República, caiu em Santos" (HERINGER, 2016, p. 95); assim como a inclusão de acontecimentos do mundo político brasileiro, como a Comissão da Verdade: "não sei se essa comissão que tem agora descobriu que meu pai estava nos porões dando remédio para os torturados" (HERINGER, 2016, p. 115); e à chamada Lei da Palmada: "Palmada pode? "Em determinadas circunstâncias, um golpe leve..." é o que dizem as revistas" (HERINGER, 2016, p. 133).

Em conclusão a esse ponto que trazemos para a discussão, vale lembrar que à época e ao espaço cultural que contribuem fortemente para o conteúdo de uma obra, Flory chama de repertório ficcional, o qual não é outra coisa senão "o húmus sóciocultural de onde o texto é proveniente que, formando o quadro ou cercadura do texto, reaparece, não com o seu sentido primeiro, mas sim valendo como um polo de interações" (FLORY, 1997, p. 37).

Em se tratando desse romance de Victor Heringer, essa época é o ano de 2014 e 2015, assim como o espaço sociocultural é o da sociedade carioca. Esse modo de construção do tempo, feita de modo quase explícito e em harmonia com as indicações de tempo que regem nosso universo, remetem a um saber que funciona fora do romance, auxiliando, sobremaneira, na fixação realista da história.

É chegado o momento, porém, de falar sobre o enredo de $\mathrm{O}$ amor dos homens avulsos, e o fazemos lançando aqui mão do chamado "esquema canônico da narrativa ou esquema quinário (por causa de suas cinco grandes etapas)" (REUTER, 2002, p. 36) para entendermos a sua intriga. Em primeiro lugar, temos o estado

\footnotetext{
1 "Rosto dos homens foi moldado por milhões de anos de soco, segundo estudo". O Globo, Rio de Janeiro, 9 jun. 2014.
} 
inicial, em que Camilo vive com os dois pais e a irmã no bairro do Queím, como ele mesmo afirma: "o bairro do Queím, onde nasci e cresci" (HERINGER, 2016, p. 11). Ainda na sua infância, o seu pai traz um garoto - Cosme - para a sua casa, a quem Camilo inicialmente odeia, mas depois amará. É com ele, Cosmim, como Camilo carinhosamente o chamava, que este descobrirá a sua sexualidade homoerótica, bem como terá o primeiro beijo e a primeira relação.

Em seguida, temos a força perturbadora: o assassinato de Cosme, cometido a facadas por Adriano, a quem Camilo amaldiçoa, desejando que "exista alma e que a sua só possa beber leite podre, diabo do mundo, candidíase do mundo! Assassino! Cansaço de Deus no oitavo dia!" (HERINGER, 2016, p. 111). Essa ação, que traz em seu bojo a terceira etapa do esquema, a dinâmica, reflete-se na longa dor enfrentada por Camilo, que passa a encarar agora uma crise existencial, representada naquilo que podemos chamar de um parágrafo-reflexão, o qual dura sete páginas inteiras, trazendo à tona vários temas: falta de amor, certeza da morte, miséria humana, homofobia etc. Esse acontecimento o moldará pelo resto da sua vida: "o assassinato tomou domínio de mim para o resto da vida" (HERINGER, 2016, p. 114).

Posteriormente, temos a forma equilibradora, a qual acontece quando Camilo, já um homem de meia idade, descobre Renatinho, neto de Adriano, e passa a cuidar dele com amor paterno, modificando o sentimento que há anos trazia no peito: ternura toma o lugar do rancor. Convém ressaltar que esse é o estado final da intriga: a ternura, ou seja, a redenção experimentada por Camilo ao amar e adotar Renatinho. Daí o testemunho claro e extraestético, realizado pelo próprio autor Victor Heringer, em sua postagem na internet no ano de 2016 :

A saída deste livro é a ternura. A ternura, mais calma que o amor e mais amável que a mera simpatia ou tolerância, é uma forma de compreender e interferir no mundo tão boa quanto qualquer outra. Ternura também é resistência. "Amai-vos uns aos outros", amar a todos, franciscanamente, talvez seja pedir demais. Afinal, como escreveu Freud no seu mal-estar, "um amor que não escolhe parece perder parte do seu valor. Além disso, nem todos os humanos são dignos de amor". Mas todos são dignos de ternura. Sede ternos! (HERINGER, 2016, on-line).

Atinente às personagens dessa intriga, podemos certamente dizer que já apresentamos brevemente algumas delas, tais como o protagonista Camilo, Cosmim, Pablo, o pai de Camilo, o assassino Adriano e o neto deste, Renatinho. Entretanto, outras personagens que detêm um papel essencial nesse enredo são: Joana, a irmã de Camilo, que sabe desde o início de sua opção sexual; Paulina, a empregada, e Maria Aína, a anciã que cuidava da casa; os amigos de infância de Camilo, no bairro do Queím, assim como os seus colegas de classe, cujas caracterizações merecem um breve parêntesis.

É claro que a caracterização de Camilo é bem mais acabada e para ela devemos voltar a atenção. Mas a caracterização de sua turma de escola merece destaque especial. Camilo, por exemplo, nasceu no ano de 1963, crescendo, portanto, na época da Ditadura. Ele é caracterizado como aleijado, "muito branco quase verde" (HERINGER, 2016, p. 12) e, por isso, desde criança ele odeia o sol. A sua turma, entretanto, é caracterizada por meio de personagens tipológicos, estende-se por cinco páginas e todos os seus colegas, em termos gerais, recebem o seguinte enquadramento: aspectos físicos marcantes, comportamentos que o caracterizaram durante os anos escolares e a vida ou carreira profissional que decidiu seguir: "A. A. de C. - Baixinho que enfeou na adolescência, depois de uma infância cheia de atenções. Compensava com um bom humor constante e forçado. Ótimo em matemática" (HERINGER, 2016, p. 39).

E, assim, muitas pessoas com as quais Camilo se encontrará ao longo da narrativa, serão compreendidas e analisadas por ele lançando mão de uma espécie de enquadramento mental delas nesses arquétipos. É verdadeiro dizer, portanto, que essa distinção de Camilo como uma personagem, cuja perspectiva do universo ficcional passa pelos seus olhos faz dele - além de narrador - a personagem focalizadora, fato que traz para a nossa discussão o segundo nível de análise narratológica, como mostraremos, que é a narração.

\section{NARRAÇ̃̃O}

Mais que tudo, nesse nível de análise são examinadas "as grandes escolhas técnicas que regem a organização da ficção na narrativa que a expõe" (REUTER, 2002, p. 59). Refere-se aqui ao modo narrativo, à voz, às perspectivas, às instâncias e à gestão do tempo ou ordem dos acontecimentos.

De acordo com Reuter, podemos argumentar que existem "dois grandes modos narrativos, que são dois grandes polos para os quais as narrativas mais ou menos tendem" (REUTER, 2002, p. 59), que são o contar e o mostrar. Concernente ao primeiro modo, nós o formularíamos assim: a mediação do narrador é visível, sabendo o leitor que a história é contada por uma ou mais consciências, e é o mais frequente em nossa cultura. Já no segundo modo narrativo, isto é, o mostrar, a narração é menos aparente, criando uma ilusão e dando a impressão de que a história está se desenrolando diante dos olhos. Relativamente a $\mathrm{O}$ amor dos homens avulsos, parece-nos impossível extrair outra conclusão que não seja a de que se trata de um contar.

O romance é, incontestavelmente, narrado em primeira pessoa do singular: " $\mathrm{Li}$ em um dos meus livros de história [...]. Nas férias de 1976, eu tinha uns treze anos de idade" (HERINGER, 2016, p. 12). Esse narrador, dizendo agora mais enfaticamente, é Camilo, pelo menos até o seguinte excerto: "o Renato vem e me dá um beijo na bochecha, a boca entreaberta. As laterais do meu pescoço, subindo até as orelhas, se agudizam" (HERINGER, 2016, p. 127). A partir daí tem início outra parte do romance, intitulada Um sol dentro de casa, com consequente mudança de narrador.

A narrativa agora é realizada em terceira pessoa, entremeada de discursos de tipo marcadamente direto, com as falas das pronunciadas diretamente pelas personagens, inseridas quase sem mediação, flertando com o modo narrativo mostrar. Não sem razão que um ponto particularmente interessante a esse respeito é que entramos na famosa ilusão do modo mostrar, com um narrador oculto. Sabemos que a narrativa se concentra no presente da vida de Camilo, que se resume 
basicamente a cuidar de Renatinho e a desfrutar de sua amizade com Grumá, e o momento é explicitamente o final do ano de 2014, mas não sabemos quem está narrando: "pela primeira vez, o Camilo vai pegar o filho olhando pela janela [...]. Como vai fazer para comprar as coisas da ceia de Natal, Camilo não sabe" (HERINGER, 2016, p. 149).

Colocando em tela essas duas partes, nas quais se divide $\mathrm{O}$ amor dos homens avulsos, nossa interpretação de base é que a sua voz narrativa - relações entre o narrador e a história que ele conta - também se divide em duas atitudes, evidenciando que nenhum texto é "puro": uma cuja história é contada por um personagem-narrador, Camilo, voltado para o passado e para a infância, e outro narrador que está ausente da história que conta, que não sabemos quem é, e que se concentra no presente e no Camilo maduro. À primeira voz chamamos de "narrador homodiegético" (REUTER, 2002, p. 81), típica "dos relatos nos quais o narrador conta sua própria vida retrospectivamente"; à segunda, de "narrador heterodiegético e perspectiva neutra" (REUTER, 2002, p. 80 ), aquela mais "objetiva". E mais: na primeira parte a mensagem se organiza em forma de narrativa; na segunda, em forma de discurso. Abaixo temos excertos exemplificando as duas vozes:

Não tenho nostalgia do meu tempo de escola (colégio São Sebastião, particular, a três quarteirões de casa, ainda existe), foi meio aguado. Serviu para aprender a ler, somar, calcular o porcento dos impostos e mais quase nada. Descobri também que a fauna humana não é muito sortida (HERINGER, 2016, p. 38).

$\mathrm{Na}$ forma de discurso direto:

O menino Renato vidrado.

TV: ... na casa onde presos políticos eram torturados $e$ mortos...

CAMILO: Muda de canal.

O garoto não ouve.

CAMILO: Renato!

TV: ... o coronel Paulo

Magalhaes, o "doutor Pablo"

quebrou o silêncio...

Renato: Paulo Magalhães foi

encontrado morto em abril de

2014... (HERINGER, 2016, p. 131132).
Enquanto as vozes narrativas concernem ao fato de contar, as perspectivas dizem respeito às focalizações ou pontos de vista, ou seja, perceber. Dos três grandes tipos de perspectivas, esse romance de Victor Heringer lança mão marcadamente de duas, pelo menos. Na primeira parte, das páginas 1 a 127 , com o narrador Camilo, temos o que Reuter (2002, p. 74) - evocando outros autores - denomina de "visão com" ou "focalização interna fixa", uma vez que a percepção passa por uma personagem. Em termos gerais de instância narrativa, é pertinente apontar que essa combinação - narrador homodiegético com a perspectiva passando pelo narrador - é própria, não somente das autobiografias e das confissões, como dos relatos em que quem narra conta a sua própria vida retrospectivamente, como é aqui o caso de Camilo.

Já na segunda parte, das páginas 129 a 152 , temos uma "visão de fora" ou "focalização externa” (HERINGER, 2016, p. 74), tendo o leitor a impressão de uma narrativa "objetiva". Analisando também em termos de instância narrativa, podemos afirmar que nessa segunda parte alguém testemunha as ações das personagens, fornecendo-nos as informações que ela sabe, as quais são limitadas. Bem por isso que a narrativa se concentra no presente da vida de Camilo, especialmente no final do ano de 2014. As voltas ao passado, nessa combinação, são limitadas e, por isso, elas são poucas, tais como esta: "Camilo nunca pulou carnaval. O Queím da infância queimava, eram os únicos dias em que a poeira bege virava amareloouro" (HERINGER, 2016, p. 142).

Voltando um pouco à combinação existente na primeira parte de $\mathrm{O}$ amor dos homens avulsos, isto é, um narrador homodiegético com a percepção passando por ele, é interessante fazer uma breve elucidação sobre um ponto que ainda merece ser destacado: a gestão do tempo. Ora, essa combinação, em nosso modo ver, diz muito sobre o ritmo dos acontecimentos no romance e de como a narrativa está estruturada. E isso porque, como o narrador homodiegético possui um saber muito mais significativo de cada uma das etapas anteriores de sua vida, ele pode, em consequência disso, manejar com absoluta liberdade as analepses e prolepses, gerando anacronias narrativas.

Em O amor dos homens avulsos, estando os capítulos dispostos de forma contínua, marcados apenas por uma simples enumeração, a gestão do tempo pelo narrador torna-se de difícil distinção, embora seja possível percebê-la. Os cinco primeiros capítulos, por exemplo, tratam da ambientação da história, com Camilo, em flashback, relembrando a sua infância. Apenas ao final desse mesmo capítulo, marcadores de tempo nos situam no presente, para a volta do homem de meia idade ao bairro onde morou há mais de trinta anos: "hoje em dia, fica a duas quadras de um dos maiores shoppings da Zona Norte e a uns quatro quarteirões do apartamento onde moro (2 qtos, 1 suíte). Depois de mais de trinta anos longe do Queím, voltei” (HERINGER, 2016, p. 18).

Muito amiúde, no romance, quase tudo é lembrança do passado, é narrativa psicológica de alguém que está a caminho de uma redenção pela ternura e que, no meio desse caminho, relata o trauma sofrido com o assassinato de seu primeiro e grande amor. A narrativa só é entrecortada, em sua primeira parte, com ações que se situam no presente quando Camilo fala do seguinte: de sua volta ao bairro Queím, da amizade com Grumá, de notícias que ouve na TV, de acontecimentos diários, como idas à padaria, da família atual de sua irmã Joana, entre outros fatos.

$\mathrm{O}$ vaivém entre esse presente e o passado vivido pelo narrador é intenso, donde se constata o uso de uma outra instância narrativa em $\mathrm{O}$ amor dos homens avulsos, que é aquela em o que o narrador conta o que acontece no momento em que acontece e não em retrospectiva. Esse jogo de relações entre as duas séries temporais, isto é, o tempo da história contada e o tempo tomado para contá-la permite-nos afirmar, em linguagem mais técnica, a existência, no romance, de duas posições básicas em termos de temporalidade: a narração ulterior, quando Camilo fala do que passou anteriormente; e a narração simultânea, quando narra o presente.

As prolepses ou catáforas, por outro lado, são trabalhadas fundamentalmente em função da dor que Camilo viveu com a morte de Cosme. Convém destacar que entre as idas e vindas entre o passado e o presente, o futuro se entremeia nos relatos, com o narrador - que já sabe o que aconteceu - evocando, inúmeras vezes, a morte ocorrida e que será narrada 
adiante. Esses adiantamentos são feitos ora com o uso de parênteses, expressando informação adicional: "(A polícia deve ter foto dele deitado cadáver, o corpo com as chagas da faca)" (HERINGER, 2016, p. 48); ora com o uso do verbo no futuro do pretérito simples: "Este era o marido de Paulina, o homem que, em alguns dias, mataria o Cosme" (HERINGER, 2016, p. 51); ora dizendo claramente que Cosme fora assassinado: "depois que ele foi assassinado, eu poderia ter virado alguém que adora demais fotos de bebês, um vitimista" (HERINGER, 2016, p. 82).

O fato adiantado por meio das prolepses só é narrado em detalhes na página 108 , indo até a página 111. São nessas páginas que se encontram a revelação: de que a morte ocorreu às 13 horas, que o corpo foi encontrado por uma mulher numa segunda-feira, que o assassino fora antes até o quarto onde estavam Camilo e Cosme e os viu nus, que o crime foi cometido com 26 facadas, que a faca desaparecera e que Cosme fora abusado antes de ser morto. Após as quatro páginas de relato do ocorrido, seguem as sete páginas com a maldição lançada por Camilo sobre Adriano.

\section{A PRODUÇÃO DO TEXTO}

No terceiro nível, nós temos a produção do texto, a saber, os aspectos que remetem às escolhas lexicais, sintáticas, retóricas e estilísticas postos em movimento pelo escritor para dar forma ao texto literário. Em essência, o tipo de discurso, a designação das personagens, o registro dominante (se próximo ou elevado do calão), figuras de estilo etc, os quais podem interagir fortemente com os dois outros níveis, refletindo as escolhas impostas pelo universo representado e pelo modo de narração, ou mesmo manter certa autonomia, refletindo o que chamamos de estilo do autor.

Principiaremos a análise da "textualização", tal como a entende Reuter (2002, p. 97), ou seja, "a montagem do texto, que concerne às escolhas do léxico, sintaxe, retórica, estilística", dando especial destaque ao tipo de discurso, o qual é, em sua primeira parte, predominantemente caracterizado como indireto livre. Mesmo o discurso direto, quando ocorre, não é marcado como se dá habitualmente, com o uso de travessões e uma linha para cada interlocutor, mas apenas distinto por meio de aspas e muitas vezes posicionado dentro do parágrafo: "deve ter notado minha cara de nojo, porque falou: "Quer ver, ossí menino, esse cheiro sabe o que é? Todas as palavras que o boi não sabe falar". Paulina riu" (HERINGER, 2016, p. 22).

Disso não segue absolutamente que não haja alguns casos de discurso direto, aqui e acolá. Mas o mais regular, nesse texto, é o uso do discurso indireto livre ou mesmo a suavização do discurso direto: "meu braço estava curado. Eu tinha destrocado o cajado pelas muletas, era aleijado em tempo integral novamente, com meus dois tentáculos metálicos. O Cosme veio e disse "Vamos lá fora?", eu "Piscina?", ele "Pra rua"” (HERINGER, 2016, p. 45).

Já na segunda parte, podemos dizer que temos um exemplo de como os níveis (ficção, narração e textualização) podem interagir fortemente. Nessa parte, as escolhas levadas adiante no nível da narração impõem mudanças também no nível da textualização. Dito de forma mais clara, o que observamos é que, a partir daí, com a mudança de foco narrativo, do narrador homodiegético para o heterodiegético, muda radicalmente também o tipo de discurso, indo do indireto livre para um marcadamente direto:

\section{CAMILO: Você conhece seu pai? GRUMÁ: Não. \\ CAMILO: Você tem filhos? GRUMA: Não que eu saiba. (Risinho)CAMILO: Sabe que vão cortar a árvore aqui da frente? Depois de amanhã. GRUMÁ: Demorou. Ajudei na vaquinha. Sabe que a velha do 701 quase quebrou o cotovelo? Tropeçou na raiz. CAMILO: A árvore não tem culpa. \\ GRUMÁ: E quando você ficar velho? (HERINGER, 2016, p. 137)}

Outra dimensão importante da montagem de um texto é a designação das personagens, chamada de designantes. Isso significa, em modo breve, levar adiante um adequado esforço em direção ao entendimento do nome das personagens, designante que, assim como na vida real, dá vida e fundamenta a sua identidade. Pois bem, é observando as unidades de base das personagens de $\mathrm{O}$ amor dos homens avulsos, que chamamos a atenção para uma certa romanização dos nomes. Como vamos mostrar, todos eles são nomes romanos e têm origem no latim. São nomes mais ou menos antigos, mais ou menos nobres e apontam para uma determinada época.

Camilo, que significa aquele que nasceu livre ou mensageiro, tem origem latina. De outra parte, o seu significado - que também significa nascido de família importante - se coaduna com a sua identidade, pois, dentre as crianças do bairro, ele era um dos poucos cuja situação familiar financeira era remediada. O nome Cosme, por seu turno, significando ordem, vem do grego, mas possui variante italiana - Cosimo - que foi amplamente utilizada na Itália por famílias influentes.

Como é possível notar, o nome do assassino de Cosme, Adriano, também é romano. É um nome relativo à região da Ádria, uma espécie de gentílico, e apresenta os seguintes significados: escuro, moreno, peludo. Cabe salientar que Adriano é marido de Paulina, a cozinheira da família de Camilo, e possui igualmente nome de origem romana. Paulina é o diminutivo de Paula, feminino de Paulo, e significa pequena. O mesmo se dá com o nome de outras três personagens: Pablo, médico e pai de Camilo, uma variante espanhola do nome latino Paulo. Joana, a irmã de Camilo, versão feminina de João e em latim é escrito Iohanna. E com Renato, o qual vem do latim, renatus, e significa renascido ou ressuscitado.

Indo mais adiante, convém falar agora do registro dominante em $\mathrm{O}$ amor dos homens avulsos, ou seja, das escolhas efetuadas no nível do léxico. Podemos certamente dizer que se trata de um léxico que indica respeito às normas e a uma cultura clássica. Nessa ótica, o único aspecto que destacamos é a presença constante de neologismos. Em essência, eles parecem menos uma tentativa de fugir à norma do que uma maneira inovadora de descrever a realidade: "papai rarrarriu dos adultinhos e olhou para mim" (HERINGER, 2016, p. 17); "como se fosse o de-sempre" (HERINGER, 2016, p. 25); "senti um ôqo-oô do fundo do esôfago, desesperado de alívio" (HERINGER, 2016, p. 55); "meu pai, cabeceira da mesa, lambeu dos beiços e fez mmmmm para agradar a cozinheira" (HERINGER, 2016, p. 84). 
Com exceção da personagem Maria Aína, anciã que cuidou de Camilo durante a infância, todas as outras parecem se aproximar no que concerne ao campo lexical. O que não ocorre com Maria Aína, mulher, anciã e adepta de religião de matriz africana, cuja fala é de tal forma construída que evoca o plurilinguismo: "sempre quem nasce assim é porque vai ficar na beira da ameaça, ossí Camilo" (HERINGER, 2016, p. 13). Em uma palavra, ocorre, no texto, uma convergência de vozes diversas, em decorrência "da necessidade de se materializarem discursos ideológicos originais, de diferentes personagens, abrangendo graus diversos de independência literária e semântica" (FLORY, 1997, p. 40).

\section{TEMÁTICA TRABALHADA: A HOMOEROTICIDADE}

Não é inútil assinalar que, embora a análise narratológica se pretenda interna, intraestética, considerando o texto essencialmente como um conjunto linguístico fechado, tal atitude se trata de uma posição metodológica necessária, tanto quanto possível, para se concentrar no problema proposto. Contudo, declarando mais enfaticamente, nenhum texto pode fazer sentido sem as suas remissões a outros textos ou referências às realidades do mundo. É tocando, então, esse plano do conteúdo que destacaremos, em modo breve, a principal temática trabalhada em $\mathrm{O}$ amor dos homens avulsos, que é a homoeroticidade.

Urge ressaltar que uma das funções do paratexto é auxiliar o leitor na interpretação do texto principal. Ele oferece informações adicionais, de teor pragmático, semântico e literário que vão dar suporte à leitura. No caso de $\mathrm{O}$ amor dos homens avulsos, o título do livro, como um dos principais paratextos de tipo verbal, estabelece o primeiro contato com o texto propriamente dito e lança luz sobre a sua primeira interpretação. É possível presumir que o leitor, ao observar o grupo de cinco palavras que formam o título, poderá identificar que se trata de um romance cuja principal temática é a homoeroticidade.

O amor dos homens avulsos, através suas remissões e referências a outros textos, toca em muitas temáticas, tais como o clima, a religião, a política, a filosofia e a crítica social. Mas podemos certamente apontar que a temática central é a sexualidade homoerótica entre dois adolescentes e, já na meia idade, a orientação abertamente homossexual de Camilo, seu narrador. Como oportunamente evoca Fernandes:

É um grande relato de um amor adolescente interrompido muito antes de os envolvidos saber até aonde seriam levados pela correnteza desse rio caudaloso que é o primeiro amor, é, noutra parte, a execução, tantos anos depois, da possibilidade de uma vingança-os termos talvez nunca sejam esses, mas talvez uma libertação de uma angústia e um ódio acumulado durante tanto tempo, para não dizer de toda uma vida (FERNANDES, 2016, on-line).

Já um cinquentão, Camilo volta ao bairro onde cresceu e também onde esse amor foi vivido, passando, agora, a rememorar os intensos catorze dias vividos com Cosmim: "eu gostaria de dizer que vivi dois anos em duas semanas com Cosmim, mas não. Duas décadas. Essas coisas não acontecem. Vivemos catorze dias. Amei cada centímetro dele, mas nem todos os minutos" (HERINGER, 2016, p. 108). Vale destacar, nesse sentido, a linguagem erótica muito franca trabalhada por Victor Heringer, como podemos observar acima, em especial quando descreve a masturbação de Camilo, ou a masturbação coletiva de seus amigos ou, ainda, este imaginando "o pau de Cosmim": "o pau de Cosmim se meteu na fita. Como devia ser? Gordo e mais mulato que o restante do corpo. Um anel de pele enforcando a cabeça. Espumaria?" (HERINGER, 2016, p. 35).

Mas um dos momentos mais expressivos sobre o amor entre Camilo e Cosmim é quando aquele declara, por trinta e oito vezes, estendendo-se por quatro páginas, que ama e amou o Cosmim assim como outras pessoas amaram os seus amores: "eu amo o Cosmim como Amanda amou Michael e Gisele amou Jean, como Suzane amou Rodrigo e como Flávia amou Rodrigo, como Chiara, Laia e Li Xin foram amadas pelo mesmo Gregório" (HERINGER, 2016, p. 71).

\section{CONSIDERAÇÕES FINAIS}

Pretendemos, nesse trabalho, levar a cabo uma "análise narratológica" (REUTER, 2002) do romance mais famoso do escritor carioca Victor Heringer, $\mathrm{O}$ amor dos homens avulsos. Trata-se de um romance recentemente publicado, em 2016, e que logrou expressiva visibilidade após o falecimento precoce do jovem e talentoso escritor. Após a sua leitura, deixamos aqui a nossa análise, passando pelos níveis da ficção, narração e produção do texto, cuja descrição poderá se mostrar útil para auxiliar no entendimento e divulgação desta obra e de seu autor.

A principal temática trabalhada é a descoberta da sexualidade homoerótica entre dois adolescentes, cujo tempo se passa na época da ditadura militar no Brasil. Podemos afirmar que as escolhas efetuadas pelo escritor para trabalhar o assunto, que pode ser considerado um tabu para muitos, foram adequadas. No nível da ficção, o formato escolhido foi a narrativa psicológica, de relatos íntimos, o que pode favorecer a identificação do leitor com os sentimentos do narradorpersonagem. E em nível da narração, ou melhor, instância narrativa, a mesma coisa pode ser dita, uma vez que a percepção passa também pelo narrador-personagem, permitindo que o leitor se sinta bem perto de suas sensações e pensamentos, ajudando na assimilação de uma temática hoje ainda polêmica.

\section{REFERENNCIAS}

FERNANDES, Pedro (2016). O amor dos homens avulsos, de Victor Heringer. 30 set. 2016. Disponível em: http://www.blogletras.com/2016/09/ o-amor-dos-homens-avulsos-devictor.html. Acesso em: 10 dez. 2018

FLORY, Suely Fadul Villibor. O leitor e o labirinto. São Paulo: Arte \& Ciência, 1997.

HERINGER, Victor (2016). Notas avulsas sobre $\mathrm{O}$ amor dos homens avulsos. Disponivel em: http:// historico.blogdacompanhia.com. br/2016/09/notas-avulsas-sobre-oamor-dos-homens-avulsos/. Acesso em: 26 nov. 2018

O amor dos homens avulsos. São Paulo: Companhia das Letras, 2016. 
REUTER, Yves. A análise da narrativa: o texto, a ficção e a narração. Trad. Mario Pontes. Rio de Janeiro: DIFEL, 2002

ROSTO DOS HOMENS FOI moldado por milhões de anos de soco, segundo estudo. O Globo, Rio de Janeiro, 9 jun. 2014. Disponivel em: https:// oglobo.globo.com/sociedade/ciencia/ rosto-dos-homens-foi-moldado-pormilhoes-de-anos-de-socos-segundoestudo-12777168. Acesso em: 30 nov 2018.
SAMOYAULT, Tiphaine. A

intertextualidade. Trad. Sandra Nitrini.

São Paulo: Aderaldo \& Rothschild, 2008.

\section{Recebido em 06 Fev 2019 ～Aprovado em 06 Jun 2019}

Gabriel Arcanjo Santos de ALBUQUERQUE.

Doutor em Letras - Literatura Brasileira pela Universidade de São Paulo. É professor associado da Universidade Federal do Amazonas no Departamento de Língua e Literatura Portuguesa. Atualmente vem desenvolvendo trabalhos voltados para a produção literária em condição insular. E-mail: gasalbuq@gmail.com.

Jamescley Almeida de SOUZA.

É doutorando em Sociedade e Cultura na Amazônia (UFAM). Possui Mestrado em Letras - Estudos Literários pela Universidade Federal do Amazonas, atuando principalmente na ficção produzida pelo escritor amazonense Paulo Jacob (1921-2003). E-mail: jamescleya@gmail.com. 